\title{
Local Dialect Radio Programmes, Rural Development and Social Integration: The Case of Nsukka Alua, Radio Nigeria, Enugu Programme
}

\section{Dominic O. Anyadike}

School of General Studies, University of Nigeria, Nsukka Anyadike66@gmail.com

\section{Charity N. Olemadi}

\author{
Staff and Presenter, Nsukka Alua Local Dialect Programme, Radio Nigeria, Enugu
}

\section{Chinedu C. Odoemelam}

$(P h D)$, Department of Mass Communication, University of Nigeria, Nsukka judahmandate@gmail.com

\author{
Doi:10.5901/mjss.2015.v6n4s2p83
}

\section{Abstract}

\begin{abstract}
The present study focuses on the contribution of the 'Nsukka Alua' local dialect radio programmes to the social integration and rural development of the Nsukka people of Enugu State, Nigeria.. A combination of ethnographic qualitative research design was used. For the field study, the interview and focused group techniques were adopted to collect the data. A multi-stage sampling technique was used to select 5 communities for the study. Data were gathered on the role of Nsukka Alua as an integrative tool, for the promotion of Nsukka traditional culture and the communication of development information that will mobilize the people for development. The study established that Nsukka Alua radio Nigeria programme, has improve awareness and knowledge of solutions to community development problems ranging from social integration, rural development, education, agriculture to local governance. Since the study showed a positive role of the indigenous radio programme, Nsukka Alua in rural development and social integration among the Nsukka people, future intervention policies for development should package more radio programmes in local language of target group. These will enhance listenership, interest and positive change of desired development and integrative behavior.
\end{abstract}

Keywords: Local Dialect, Radio programmes, Rural Development, Social Integration, Nsukka Alua

\section{Introduction}

Studies, (Khan 2012; Walters et al, 2011; Isa 2005:76; Allimi 2005:23; Bashir 2005:89) show that a decisive role can be played by communication in promoting human development in today's new climate of social change and language is a major tool in the communication process. As the world moves towards greater democracy, decentralization and the market economy, conditions are becoming favorable for people to start steering their own course of change. But it is vital to stimulate their awareness, participation and capabilities. Communication skills are central to this task but at present are often under-utilized. Policies are needed that encourage effective planning and implementation of communication programmes and strategies.

The management of Nigeria's multi ethnic, religious and linguistic diversity to foster peace, unity and national integration has remained a critical challenge to development aspiration (Ayakoroma, 2011:12).Ayakoroma argues further that the reality of the country's ethno-cultural and religious composition presents an unfortunate situation, where sectional interest, and ethnic affiliation rather than loyalty to national development goals and aspirations. He concludes that the development of nations like Brazil, China, Japan, India, Malaysia, South Korea, and so on, have been largely shaped through arts, culture, and language. This is based on the realization that cultural values such as language, dressing, kingship system, marriage traditions, festivals, naming and funeral ceremonies, and other such core values, are veritable avenues for development (Ayakoroma, 2011:12).

As a cultural manifest, language could be used as a means for mobilizing ethnic groups for specific development purpose (Moemeka, 2012; Ayakoroma, 2011, Odoemelam et al, 2013; Odoemelam et al, 2015). The assumption is that, 
people would respond more to a local language with which they have a frame of reference (Odoemelam, 2015). Language, in the first place, is an organized system of speech used by human beings as a means of communication among themselves. It is such differentiated system of speech as used by a section of the human race, for example, the English language. It is also describe as a system enriched by words and phrases used by persons having special knowledge. Languages are in a constant process of change, in sound, in form, and in meaning, so long as they are spoken. The evolution of language is generally from complex forms to simpler and more freely combinable elements (Ayakoroma, 2011, p.12).

Though the government is spending millions of Naira in the name of rural development, but still it is not getting the desired results. There can be many reasons behind this. But the first and the foremost reason is the communication gap between government devised policies and common masses. Though, the policies are extremely good, but common masses remain ignorant regarding them. What should be done to bridge this gap? Studies have proposed a firm communication policy. According to this policy, local dialect radio programmes should be promoted in order to enhance community development and integration.

This study examines how this cultural phenomenon, language, could help in rural development and social integration of the Nsukka people. The role of the radio Nigeria, Enugu programme Nsukka Alua local dialect programme in harnessing resources for rural development and integration, will form the fulcrum of this investigation.

The Nsukka people are found in the South eastern part of Nigeria in Enugu State. They occupy the North senatorial zone and speak the general Igbo language which is the major medium of expression among the south easterners comprising Enugu, Abia, Anambra, Imo and Ebonyi States. However, the indigenous language of the Nsukka people is called 'Ideke'. The 'Nsukka Alua'is a variation of the 'Ideke' Nsukka indigenous dialect specie. Nsukka Alua radio Nigeria programme, is a thirty minutes chit-chat programme in Nsukka dialect. It features activities, cultures and achievements of the people or organizations in Nsukka cultural zone. The programme is designed to unite all Nsukka people in Nsukka cultural zone towards developmental goals that affect the zone.

\subsection{Statement of Problem}

In developing economies like Nigeria, majority of the citizens live in the rural areas where agrarian culture constitutes the major micro economic activity. As a result, most development oriented agenda are focused on such areas. One of such development agenda is the use of the radio and a local dialect medium to disseminate relevant information that will improve life style and integrate the people for productive enterprise. Where such information gap exists it has led to failure and non-realization of development objectives and lack of social integration which may culminate in increase in social vices.

Unarguably, the mass media are tools for information dissemination and mass education of the people for social transformation of the society because they have the power for promoting social cohesion and integration of the component units of a nation. Therefore, they are critical to national cohesion and development aspirations especially where language differences hold sway. Previous literature show that, in a decent and healthy democracy, mass media are regarded as the purveyors of public messages to the heterogeneous and scattered audiences through the channels of radio, television, newspapers, magazines, internet among others. Among the mass media genre, the radio is the most acclaimed partner in progress where developing objectives are concerned. This is especially so due to radio's pervasiveness and use of indigenous language in the dissemination of anticipated behaviour change messages. The above notion about the radio has stimulated various scholarly debates addressing the role of radio in achieving development but such efforts have largely ignored empirical examination of how local dialect programmes contribute to rural development and social integration. This has resulted in the dearth of literature in Nigeria, on the role of local dialect programme in rural development and social integration. Against this backdrop, this paper examines the influence of the Nsukka Alua radio programme on rural development and social integration among the Nsukka people of Enugu State, Nigeria.

\subsubsection{Objectives of Study}

The general purpose of this study is to examine the influence of the Nsukka Alua radio programme on rural development and social integration. Specifically, the study will:

- Determine the level to which local dialect programmes contribute to improved life style among the Nsukka people.

- Evaluate the extent to which 'Nsukka Alua' programme integrate the Nsukka people.

- To ascertain if local dialect programmes have the capacity to mobilize the people for development. 


\subsubsection{Research Questions}

The study will attempt to answer the following questions:

- To what extent do local dialect programmes contribute to improved life style among the Nsukka people?

- How has 'Nsukka Alua' programme contributed to the integration of the Nsukka people?

- What is the extent to which local dialect programmes mobilize people for development?

\subsection{Significance of the Study}

This study is significant and relevant to all strata of human society because it is aimed at helping people at all level to communicate and empower them to recognize important issues and find common grounds for action and build a sense of identity and participation in order to implement their decisions. It will also be significant because it will contribute to the literature on language and national development. Finally, the media industries will find it very relevant because it will show the importance of local dialect programmes in mobilizing for socially accepted goals.

\subsection{Literature Review}

While this study's interest is on rural development news, it is also in place to examine the generic concept of development and by extension, development news. From the macro point of view, development refers to the change from simple forms of organization and production to complex modern ones. Originally men and women lived in small, self-sufficient communities, dependent on things they found in their environment. if food, fuel, or materials ran out, they would simply move on. One of the first significant social and technological developments was the transition from this nomadic way of life to agricultural cultivation in settled communities, from which began societies as we know them today (Coldevin, 1988). So, this phenomenon will be termed as development, though in the materialistic sense. Rather, development is a wholesome process. Ngwu (2010) sees rural development as improving the living standards of the masses of the low income population residing in rural areas and making the process of their development, self-sustaining.

Development does not mean only economic growth but also the social, spiritual and moral enhancement of the entire society or nation. Economists defined development as the growth in terms of structural and technological advancement. Typically, in the early stages of development economies have most of their production and labor force in agriculture. Later, the manufacturing and service sectors became larger (Kahn, 2012).

Another key feature of development is to eradicate poverty. Entire economies can be poor, or they can grow but still leave large sections of their people in poverty. In the second half of the 20th century, development policy makers became acutely aware of the difficulties a large number of countries in the developing world facing as most of them were former colonies of the industrialized nations (George et al, 2013). Development economics became more or less synonymous with the study of how these countries could progress out of poverty. Now-a-days no one can deny the importance of media in fighting social evils, illiteracy as

well as poverty (Kahn, 2012).

$>$ Development Indices:

- Human Development (Education)

- Economic Development (Skill and Craft Entrepreneurship)

- Social and Cultural Development (Integration and knowledge of the people, Healthy living and unhealthy traditional practices)

- $\quad$ Physical Development (mobilized to build self help projects like bore-holes community schools, feeder roads) (Barr, 2005; Coldevin, 1988; Odoemelam et al 2013).

There have been several cited cases (Khan, 2012; FAO, 2009; Manda, 2007) of failures in projects and programmes in development, due to misunderstanding between development communication providers and their audience either around cultural differences, policy explanation and concepts. Knowledge and information can only be useful when they are communicated clearly without misunderstanding and ambiguities. In rural development, for instance, it has been argued that sustainable development can succeed only when development issues are communicated in processes that will help rural people to exchange experiences, find common ground for collaboration and actively participate in and manage rural development activities. Language plays important role in determining the level of cooperation that would be accorded any mobilizing goal. That is why Anyaegbunam (2005) observe that "indigenous language programme encourage socio-cultural cohesion and unification. The conclusion is that a vigorous 
promotion of these programmes and other identified unifying national symbols would engender the much needed national integration and peaceful co-existence in Nigeria". In his analysis, Yusuf (2005) affirms that language is the chief by which beings communicate with each other (Ejele, 1996; Fani-Kayode, 2005). No doubt, this is important for development objectives.

Language as Ayakoroma, (2011) notes, is an organized system of speech used by human beings as a means of communication among themselves. It is such differentiated system of speech as used by a section of the human race, for example, the English language. It is also describe as a system enriched by words and phrases used by persons having special knowledge. Languages are in a constant process of change, in sound, in form, and in meaning, so long as they spoken. The evolution of language is generally from complex forms to simpler and more freely combinable elements.

Okunna (2004:18) sees development as a process of social change which has as its goal the improvement of the quality of life of all or the majority of the people, without injuring he national and cultural environment in which they exist and which seeks to involve the generality of the people as closely as possible in this enterprise. To Walter et al (2011), development simply means the process by which societal conditions are improved. These societal or human conditions include the social, physical and environmental conditions. Manda (2007) sees rural development as improving the living standards of the masses of the low income population residing in rural areas and making the process of their development, self-sustaining.

\subsubsection{Local Language as Cultural Manifest}

The Cultural Policy for Nigeria (1988) defines "culture" as: the totality of the way of life evolved by a people in their attempts to meet the challenge of living in their environment, which gives order and meaning to their social, political, economic, aesthetic and religious norms and modes of organization thus distinguishing a people from their neighbours

It is also pertinent to note that the policy states that culture comprises material, institutional, philosophical and creative aspects. The material aspect refers to artifacts like tools, clothing, food, medicine, utensils, housing, etc; the institutional deals with the political, social, legal and economic structures erected to help achieve material and spiritual wellbeing of the people; the philosophical is concerned with ideas, beliefs and values; while the creative concerns a people's literature (oral and written) as well as their visual and performing arts, which are normally molded by, as well as help to mould other aspect of culture. Thus, culture encompasses arts and other ways of life of a people that give meaning and order to the environment they live in (Yusuf, 2005).

According to Newhill and La Pagila (2006), culture has been called "a blueprint for living," in the sense that it is a pattern of living that is expected of people. Every person is born into an existing culture, which must be learned and which shaped his/her life. This explains why the social scientist sees culture as the entire way of life within a society. In other words, the way a people think about problems of living the tools, houses and customs they have adopted as their own are part of the culture of a people.

Man as a social being cannot live outside his society and the order governing the conduct of affairs. Cultures emerge as shared historical experiences of a given society which, of course, is continuous and ever changing and developing (Jimada 1). Culture is not merely am return to the customs of the past. It embodies the attitude of a people to the future of their traditional values faced with the demands of modern technology which is an essential factor of development and progress. Cultures do not exist in isolation as human groups relate to one another; hence there is borrowing and fusion. For example, cultures evolve from that of others who are their immediate neighbours. This could be deduced from the language, religious worship, festivities, and other cultural elements. Culture cuts across identities and boundaries; this is because of the historical relations between groups in terms of trade, inter-tribal marriages, and diplomacy, which lead to borrowing in terms of language, religion, arts, dresses, etc.

There are situations where we experience what we call "culture gaps" and "culture shock." According to the Webster's Dictionary, the former is where there are radical differences in lifestyles between the advanced cultures and developing/underdeveloped countries; while the latter is the traumatic effect of disorientation caused by a major change in milieu experience by new inhabitants (235). Ayakoroma (2011) examines the phenomena in his analysis of Culture and Globalisation thus:

Interconnection generally results from superimposition caused by migration or mobility.... Single cultural elements can often be tracked back along their historical way to one of the original cultures. The number of cultures decreases exponentially during the syntheses' processes. 


\subsubsection{Theoretical Perspective}

\subsubsection{Participatory Communication Model}

The theory of participatory communication as espoused by Mefalopolous (2008) and Moemeka (2012) contains useful concepts that are relevant to a discourse on the influence of local dialect programme on rural development and social integration. The main tenet of participatory communication is the concept of inclusiveness. It argues that for development to occur there is need to enlist the support of those for whom the development objectives are designed. Development communication literatures (Odoemelam, 2013; Mefalopolous, 2008; Moemeka, 2012) suggest a dialogic mode of communication. Dialogic communication envisages a process of commonness in the interaction continuum. Empirical literatures have shown that language (indigenous) achieves the objective of participatory communication (Yusuf, 2005; Fani-Kayode, 2005; Anyaegbunam, 2005).

Anyaegbunam (2005) argues that indigenous language programme encourage socio-cultural cohesion and unification. He concludes that a vigorous promotion of indigenous language programmes and other identified unifying national symbols would engender the much needed national integration and peaceful co-existence in Nigeria. In their analysis, (Yusuf, 2005; Ejele, 1996; Fani-Kayode, 2005) affirmed that language is the chief by which beings communicate with each other. No doubt, this is important for development objectives.

In this study, we argue that participatory communication can serve as a strategic tool to achieve pre-established programmatic goals (for example, participatory community development). However, participatory communication can also envisage a fundamentally new approach to development, one which sees communication as the very objective of development effort. Participatory communication can be construed as a channel of self-expression and self-management for self-development (Wimmer and Dominick, 2006). Including the voices of the marginalized and underprivileged, communication processes can become more inclusive and open-ended rather than goal-oriented, and may provide a venue to directly address structural problems. The consensus among contemporary development specialists is that participatory approaches have rendered the modernization paradigm obsolete, at least on the theoretical level. Participation has indeed been officially sanctioned as the preferred communication strategy by a number of international development organizations including UNICEF, UNDP, FAO, and the World Bank. This is axiomatic to this study because rural development and integration of the people would require the people's participation and to promote inclusiveness, indigenous language performs the role of mediation.

\section{Methodology and Selection of Participants}

The Ethnographic research design, which is qualitative and participatory in nature, was adopted for this study (Creswell 2002). Cresswell notes that this research design allows for the combination of a mixed method (p.565). This involved the broad techniques of interview and focused group discussion (Dagron, 2001). Justification for the use of these qualitative techniques was informed by the researcher's interest in knowing the attitudes and opinions of Nsukka residents on the influence of local dialect programmes like Nsukka Alua on rural development and community integration (Barr, 2005). It is important to note from the onset that the present study is merely exploratory; it avoids the use of hypotheses because knowledge in the area is marginal and lacks standardized substantive predictions (Wimmer and Dominick, 2011). Considering the participatory nature of the present study, the ethnographic techniques adopted (focused group discussion and interview techniques) were thought to be most suitable (Suter, 2000). There are numerous advantages associated with using these techniques one of which is that it allows participants to participate fully in the process of facts finding (Seidu et. al, 2011).

Indigenes of Nsukka constituted the population of this study. According to the 2006 census figures, obtained from the National Population Commission (NPC), the Nsukka senatorial zone has a population of 374,515. According to Ohaja (2003,p.75), "the population for a study refers to all those persons or things that fall under the umbrella of the topic or that can be examined to address the research problem or meet the research objectives".

The sample size was 45. This was made up of those assumed to be knowledgeable in the subject matters that constitute the variables of the study. Wimmer and Dominick (2006:13) and Ogbuoshi (2006:8) justify the need to select a manageable sample and notes, "it is not generally feasible to interview the entire population." Therefore the purposive method was adopted in the selection of the sample to be studied. A total of 40 participants were used for the focused group discussion (FGD), while 5 persons were selected for the interview technique. This gave a total of 45 participants in the study.

The Multi-sampling technique was adopted. This included the cluster sampling and the purposive sampling 
techniques. For the cluster sampling, Nsukka was divided into 5 pre-existing clusters and the cluster yielded the following:

1. Obukpa

2. Nsukka

3. Alor Uno

4. Opi

5. Eha Alumona

The purposive method was used in selecting the participants for both the focused group discussion and interview session from the identified clusters. The purposive method was adopted because it was important to select the group that had the required characteristics as suggested by Ohaja (2003). It was decided that since the subject matter was on development, it was better to seek the views and opinion of the major stakeholders in the communities within each clusters. In a traditional system of governance, the chiefs and Igwes (Paramount Rulers) constitute the stakeholders who hold community development and governance in trust for the communities. This therefore informed the selection of these traditional rulers as the participants and the interviewees respectively. Thus, from each of these clusters, 8 chiefs (called 'Onyishis'.i.e the eldest males in each community), were purposively selected from the council of chiefs for the focused group discussions. That is, 8 participants from each of the clusters. This gave a total of 40 participants in the focused group discussion and a total of five (5) focused group discussion (5 FGDs).

For the interview method; since the clusters that make up Nsukka zone had been identified and they include: Obukpa, Nsukka, Alor Uno, Opi, Eha Alumona, the Igwes (Paramount rulers) of each of the five clusters were selected for the interview. This yielded 5 interviewees, each from a cluster.

The interview schedule and focused group discussion schedule were used as the instruments for data collection. For the focused group approach, the data collected for the study were both Expected Responses (ER) and Emergent Responses (ER). Expected responses (ER), refer to those likely qualitative data/answers collected in the field, which the researcher was looking out for from the participants, while the Emergent (ER) data, refers to quite unlikely data/answers upon which the researcher stumbles in the field.

To eliminate bias and ensure objective collection of data, the researcher made use of a tape recorder to gather the information from both the interview and the focused group discussion sessions. Thereafter, the content of the tape recorder was transcribed into a written form, with each participant's views clearly represented in their order of presentation.

This study used the qualitative research technique therefore, data was analysed qualitatively. This meant that the data was not quantified statistically (Wimmer and Dominick, 2011). This involved first, transcribing the recorded interviews and focused group discussions then, matching them against the questions raised in the schedules and trying to group them into Similar (S) or Near similar (NS) opinions or views. A representation of the different opinions as expressed by the respondents on the subject of inquiry was done objectively. This style of presentation gave a better view of the respondents' opinions on whether Nsukka Alua programme influences Nsukka people towards developmental goals.

The participants in each group were given tags (1-8) representing categories in each group (CED). Each alphabet: 1-2-3-4-5-6-7-8. represented the view of a particular participant in all the five (5) focused groups discussions (5 FGDs). Each of the categories were collated and presented as total categories in the groups (TCGs). A total of 8 participants made up a group in a cluster. Each cluster was tagged a group. For easier identification and analysis, each group was identified with an alphabet A-E. Thus, there were five (5) groups namely: Group A= Obukpa Cluster; Group B= Nsukka Cluster; Group C= Alor Uno Cluster; Group D= Opi Cluster; Group E= Eha Alumona Cluster.

\section{Results and Discussion of Findings}

This study revealed quite interesting things pertinent to the objectives of the study. The qualitative method was used as a method. Thus, the focused group segment, revealed certain emergent view points. This was not unexpected since studies (Suter, 2000; Osuala, 2005) have shown that focused group method and interview are very reliable for gathering data in studies where there is need to get in-depth insight and information on the opinion and views of the respondents. The paragraphs below will present and interpret the results and findings in this study.

\subsection{Research Question 1: To what extent do local dialect programmes contribute to improved life style of the Nsukka people?}

To answer this research question, the researcher raised 3 questions. The first question sought to know if the participants 
listen to radio Nigeria, Enugu station. This was to ensure that the participants would have the locus standi to discuss the subject matter.

Participants in all the groups answered in the affirmative. However participants in the Opi, Alor Uno, and Eha Alumona Clusters, noted that even though they listen to radio Nigeria, most of the programmes are quite not relevant to their tastes. In response to this, the researcher asked what they meant. They responded that most of the programmes do not address issues that are relevant to their agricultural and economic development. This opinion was noted as Emergent opinion (EO).

The second question asked the participants if they expose themselves to "Nsukka Alua" programme. All group participants listen to Nsukka Alua programme. Again this preliminary verification was important so as to make their individual contributions to discussion valid.

The third question wanted to know what the participants think of development information on Nsukka Alua programme (What do you think is the relationship between a local dialet programme and rural development).

There were divergent views by the discussants on this issue. Participants in Group one that is, Obukpa Cluster, believe that most of the content on Nsukka Alua programme were issues pertaining to social integration of the people as a cultural group. They noted that it gives them a sense of unity and belongingness. An emergent view that was opined by one of the participants was that the programmme's discussions in this regard, was similar to a programme on Lion F.M (a community radio located within the University of Nigeria Campus but that has a reach covering all the areas within the clusters selected for this study) called 'Nsukka Deje'.

Findings to research question 1 show that:

i. Participants listen to Nsukka radio

ii. They eually listen to Nsukka Alua programme

iii. Nsukka Alua radio programme contribute to development by:

iv. Fostering a spirit of belongingness

v. Emphasizing self development opportunities by promoting the acqusistion of formal education.

vi. Promoting entrepreneurial values

vii. $\quad$ By mobilizing the people for development initiatives

viii. Integrating the people through cultural activities

From the analysis above, it is obvious that the discussions by the focused group participants hinged on one aspect of development strategy or the other, as applied by the Nsukka Alua local dialect programme. All five view points as identified by the participants, are in consonance with the points raised in the literature review that focused on local dialect radio programme contents and strategies that could foster development among a people (Moemeka, 2012). Thus, Research question one, has been adequately answered by these responses. This could be deduced from the responses by the participants in these clusters that pointed at the fact that because the contents of the programme were conveyed in the Nsukka local dialect, it gave it more credibility and acceptability.

\subsection{Research question 2. How has 'Nsukka Alua' programme contributed to the integration of the Nsukka people?}

The findings show that Nsukka Alua has contributed to social integration in Nsukka by:

i. Featuring enlightenment information

ii. $\quad$ Promoting school enrollment and skill acquisition

iii. Featuring issues that teach diligence and ambition

iv. Knowledge on self development

To adequately provide an answer to this question, interview was further conducted to see if the response will be complementary or contrary.

Findings from the interview conducted showed that Nsukka Alua was:

i. $\quad$ Serving as a unifying factor

ii. Development of the human person

iii. Encouraging the people to see themselves as brothers sharing similar cultural and political aspirations.

Both responses complement each other thus the research question, how has 'Nsukka Alua' Programme contributed to development in Nsukka, has been adequately answered by answers and discussions proffered by the participants and interviewees wherein they noted that the Nsukka Alua radio programme has influenced different aspects of their economic, social and physical life. These indices, are known to be parameters for judging development:

i. Socialization and Cultural transmission

ii. Community development projects such as, market roads, daily thrift, etc. 
iii. Scholarships and foundations for assisting indigent students.

These findings are in consonance with the works of Coldevin, (1988); Odoemelam et al (2015) and Dickson et. al. (2013).

\subsection{Research Question 3: What is the extent to which local dialect programmes mobilize people for development?}

The interview finding showed the following:

i. Local dialect programmes will make more impression on the audience than general language programmes

ii. Local dialect programmes are seen as mobilizing agency by which the target rural audience could be organized towards achieving development goals.

iii. Local dialect programmes, which are a disconnect from the target audience's frame of experience cannot make much difference.

iv. Local dialect programmes which are lacking in substance will not make any impact on the people. Therefore producing programmes or behavior change communication for the rural people, should involve the people in a two process.

An analysis of the views expressed in these discussions by the focused group participants and the interviewees, as presented above, adequately answered the research question which sought to ascertain if Local Dialect Programs Mobilize People for Development. From their responses it could be ascertained that Nsukka alua radio programme, has influenced the respondents to take one developmental initiative or the other. Also it was observed that, not only the participants who had been influenced but other listeners too. It is the contention of Mefaloplous (2008) that dialogic communications, in this instance the use of indigenous language (dialect) creates affinity and could be used as a means of mobilization for development aspirations.

\section{Summary and Conclusion}

The study set out to examine the influence of local dialect radio programmes on rural development and social integration among the Nsukka, of Enugu State Nigeria. The case study was the Nsukka Alua radio programme of the Radio Nigeria, Enugu. It looked at aspects of development relevant to a rural audience. Specifically, it ascertained if Nsukka Alua radio programme was able to influence the people, it also considered the ability of the programme to mobilize the people towards development objectives. These tasks were prompted by the notion of participatory communication. Finally, the study compared the target audience's preference for local dialect radio programmes to other similar content programmes which are not in local dialect.

The study concludes that radio plays a pivotal role in making the masses aware about their basic rights and duties. Not only limited to solving problems which they face in their day-to-day lives. But specifically, local dialect radio programmes provide a strong platform from where development ideas can freely be disseminated among the community members in the best possible manner within the context of dialogic or participatory communication process. Thus, local dialect programmes become one of the important instruments in strengthening development efforts and integrating the people. Besides solving social problems as well as entertaining local people, this also acts as an intermediary between the government policies and the local masses. This is the place from where local people can air their grievances to the government as well as get the solutions to their problems too. In conclusion, local dialect radio programmes play a major role in bridging the communication gap between the government and the local people and has proved to be one of the effective mode of communication at the grass-root level. This is the main argument of the theory of participatory communication.

\subsection{Limitations of the Study}

Even though the qualitative approach employed in the present study, has produced very enriching and valuable knowledge with regard to the contributions of local dialect to rural development and social integration, it is difficult to rely on these predictions because they are not based on hypotheses derived from extant predictions.

However, it is suggested that, because knowledge in this area is only emerging, future studies should use quantitative methods and data for reliable predictions on the influence of local dialect on rural development and social integration. Knowledge gained from the present study could serves as baseline data in that regard. 


\subsection{Recommendations}

i. Since the study showed a positive role of the indigenous radio programme, Nsukka Alua in rural development and social integration among the Nsukka people, future intervention policies for development should package more radio programmes in local language of target group. These will enhance listenership, interest and positive change of behavior.

ii. Local dialect programmes which are lacking in substance will not make any impact on the people. Therefore producing programmes or behavior change communication for the rural people, should involve the people in a two way dialogic process. This is in consonant with the theory of participatory communication.

iii. It is recommended that local dialect radio programmes should be promoted among other radio stations programmes (public and private) in the various geopolitical zones of Nigeria in order to enhance community development, at least at grass root level.

\section{References}

Allimi, T. (2005). Cultural Journalism. In Yusuf (2005). (Ed). Culture and the Media In Nigeria. Pg. 50.

Anyaegbunam, N. (2005). The media and cultural orientation. In Yusuf 2005). (Ed). Culture and the Media in Nigeria. Pg. 50.

Arinze, E; and Iheanacho, E. (2004). Nigeria: A cultural perspective to peace advocacy. Enugu: Fourth Dimension publishers.

Ayakoroma, F. (2011). Arts, culture, language and national integration. Lecture delivered at the National Institute for Policy and Strategic Studies (NIPSS). Kuru, Jos Plateau State, April 21.

Barr A. (2005). The contribution of research to community development. Community Development Journal; 40(4): 453-458.

Bashir, A. (2006). Some perspectives in Nigeria's cultural heritage in peace maintenance and in conflict resolution. In Culture and Education for Peace, Lagos: NICO.

Cultural policy for Nigeria: Federal government Printer, 1988.

Creswell, J. (2002). Educational research planning, conducting and evaluating quantitative and qualitative research

Dagron A. (2001). Making waves: Stories of participatory communication for social change. New York: The Rockefeller Foundation.

Dickson, B. U; Dikeocha, D. C and Dotimi, E. (2013). Newspapers' coverage of rural development news in Nigeria: A study of Daily Sun, The guardian and Thisday. Unpublished thesis department of Mass Communication, University of Nigeria, Nsukka.

Ejele, P. (1996). An introductory course on language. Port Harcourt: Uniport Press.

Fani-Kayode, L. (2005). Culture and the electronic media. In Yusuf 2005). (Ed). Culture and the Media in Nigeria. Pg. 50.

FAO. (2009). Rural radio: A communication tool for rural communities. Communication for Development Group.

Isa, M. (2005). Culture and the media: An overview. In Yusuf (2005)(Ed). Culture and the Media in Nigeria. National institute for cultural orientation. Abuja. Pg. 7.

Khan, S. (2012). Role of community radio in rural development. European Network For Rural Development.

Kolade, C. (2002). Refurbishing the expression of community in the Nigerian nation: The role of culture. NCAC honors lecture series. 2002.

Manda, D. (2007).Understanding development in the Third World: How communication can enhance development. Development education review. Issue 4 (2007).

Mefalopulous, P. (2008). Development communication sourcebook: Broadening the boundaries of communication. The World Bank, Washington, D.C.

Moemeka, A. (2012). Development communication in Action: Building understanding and creating participation. New York: University press of America.

Newhill, E. and La Pagila, U. (2006). Exploring world cultures. Lexington, Massachusetts: Ginn and Company.

Odoemelam, C. C. Ebeze, V; Okeibunor, N. and Anyadike, D. (2015). African communication systems and the preservation of indigenous culture: Implications for cultural and sustainable development. Journal of Interdisciplinary essays. Publishers www.grinverlag.com Munich, Germany Volume 7, 2015.pp 201-214.

Odoemelam, C. C. Okebunor, N. and Nwafor, A. (2013). Newspaper editorial frames of security issues in Nigeria: Implications for development objectives. International Policy Brief Series, Social Science \& Law Journal of Policy Review \& Development Strategies. Vol. 3, N0. 2, Pp. 1-10.

Ogbuoshi, L. (2006). Understanding research methods and thesis writing. Enugu: Linco Enterprize Ltd.

Ohaja E. (2003). Mass communication research and project report writing. Lagos John Letterman Ltd.

Okoro, N. (2001). Mass communication research: issues and methodologies. Nsukka: AP Express publishers.

Osuala E. C. (2005). Introduction to research methodology, Onitisha Africans First Publishers.

Seidu, A; Alhassan, A and Abdulai, A. (2011).The Role of Community Radio in Livelihood Improvement: The Case of Simli Radio. Journal of field Actions. Vol. 5.

Suter, E. A. (2000). Focus groups in ethnography of communication: Expanding topics of inquiry beyond participant observation. [40 paragraphs]. The Qualitative Report [On-line serial], 5(1/2). Available: http://www.nova.edu/ssss/QR/QR5-1/suter.html Retrieved 2013-7-14.

Walters D, James R, and Darby J. (2011) "Health Promoting Community Radio in Rural Bali: an Impact Evaluation". Rural and Remote 
Health 11 (online), 2011: 1555. Available from: http://www.rrh.org.au

Wimmer, R. \& Dominick, J. (2006). Mass media research: An introduction. (8th ed).Canada: Thomson Wadsworth Publishing Company Yusuff, J. (2005). Culture and the media in Nigeria. National Institute for cultural orientation. 